Article

\title{
High Normal Range of Free Thyroxine is Associated with Decreased Triglycerides and with Increased High-Density Lipoprotein Cholesterol Based on Population Representative Data
}

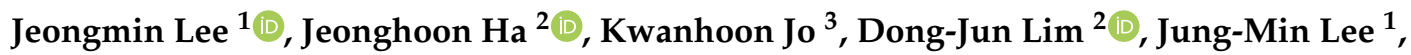 \\ Sang-Ah Chang ${ }^{1}$, Moo-Il Kang ${ }^{2}$ and Min-Hee Kim ${ }^{1, *}$ \\ 1 Division of Endocrinology and Metabolism, Department of Internal Medicine, Eunpyeong St. Mary's \\ Hospital, College of Medicine, The Catholic University of Korea, Seoul 03391, Korea; \\ 082mdk45@catholic.ac.kr (J.L.); leejm68@catholic.ac.kr (J.-M.L.); sangah@catholic.ac.kr (S.-A.C.) \\ 2 Division of Endocrinology and Metabolism, Department of Internal Medicine, Seoul St. Mary's Hospital, \\ College of Medicine, The Catholic University of Korea, Seoul 06591, Korea; hajhoon@catholic.ac.kr (J.H.); \\ ldj6026@catholic.ac.kr (D.-J.L.); mikang@catholic.ac.kr (M.-I.K.) \\ 3 Division of Endocrinology and Metabolism, Department of Internal Medicine, Incheon St. Mary's Hospital, \\ College of Medicine, The Catholic University of Korea, Incheon 21431, Korea; lovi@catholic.ac.kr \\ * Correspondence: benedict@catholic.ac.kr; Tel.: +82-2-2030-4348
}

Received: 7 May 2019; Accepted: 27 May 2019; Published: 28 May 2019

\begin{abstract}
Background: We aimed to evaluate the association between thyroid hormone (free thyroxine, free T4) level and lipid profiles in nationally representative data. Methods: This study was based on cross-sectional survey data from the sixth Korea National Health and Nutrition Examination Survey IV. After exclusion of subjects with a history of thyroid disease or abnormal thyroid function test and those on medication for dyslipidemia and/or cardiovascular disease, a total of 3548 subjects were included in the study. Results: There was a significant decrease in serum triglyceride levels and increase in serum high-density lipoprotein (HDL) cholesterol levels with high free T4 quartiles after adjustment for confounding factors ( $p$ for trend $=0.001$ and $p$ for trend $=0.014$, respectively). Risk of hypertriglyceridemia was significantly decreased (odds ratio of 0.72 (95\% confidential interval 0.53-0.98)) in the highest free T4 quartile compared to the lowest free T4 quartile, $p=0.044$ ). Conclusions: Serum free T4 levels within normal range negatively correlated with serum triglyceride level and positively correlated with HDL-cholesterol level. Therefore, a close surveillance in terms of lipid profiles could be considered in subjects with low normal serum free T4 levels.
\end{abstract}

Keywords: euthyroid; thyroid hormone; dyslipidemia

\section{Introduction}

Thyroid hormones play a pivotal role in the regulation of lipid metabolism. They directly regulate hepatic lipid metabolism including de novo lipogenesis, triglyceride (TG) assembly, lipolysis, fatty acid oxidation, and biosynthesis and clearance of cholesterol [1]. They change the composition of lipoproteins by reducing serum low-density lipoprotein (LDL) cholesterol through stimulating LDL-receptor genes [2]. Thyroid hormones also activate the cholesteryl ester transfer protein (CETP), which transports cholesteryl esters from high-density lipoproteins (HDL) to very low-density lipoproteins (VLDL) and TG [3]. Additionally, thyroid hormones affect lipid regulation from extrahepatic organs, such as adipose tissue, intestines, and muscle [4]. As they affect both efflux and influx of lipid metabolism, physiologically, they are expected to have a crucial role to maintain homeostasis of 
cholesterol. Although it not clear or determined that subtle changes of thyroid hormone levels within normal ranges could cause significant alterations in lipid profiles, overt changes are expected to cause a deterioration of cholesterol homeostasis.

Significant changes in lipid profiles have been reported in overt thyroid dysfunction [5-10]. Although changes in TG, VLDL, and HDL levels have been reported in various instances, it is consistently observed that total cholesterol and LDL-cholesterol levels are increased in overt hypothyroidism and decreased in hyperthyroidism [11,12]. Alterations in lipid profiles in the presence of subtle changes such as subclinical thyroid dysfunction have also been widely observed. In contrast to findings in overt hypothyroidism, no conclusive agreements have been made in lipid profile components in subclinical hypothyroidism, which is characterized by elevated levels of thyrotropin (TSH) and thyroid hormone in the normal range [13,14]. In some studies, total cholesterol and LDL-cholesterol, TG, and HDL-cholesterol levels in subclinical hypothyroidism subjects were not different from those in euthyroid subjects [15-17]. Conversely, other research has reported significantly higher levels of total cholesterol, LDL-cholesterol, and TG were found in patients with subclinical hypothyroidism than in euthyroid subjects [18]. In patients with endogenous and exogenous subclinical hyperthyroidism, a decrease in HDL-cholesterol was observed [11].

In addition, only a few studies have evaluated the association between thyroid function and serum lipid profile components in subjects with normal thyroid function. Roos et al. reported a negative correlation between free T4 and total cholesterol and LDL-cholesterol in euthyroid subjects [19]. De Jesus Garduno-Garci et al. reported a positive correlation between free T4 and HDL-cholesterol and between TSH and total cholesterol and TG in both euthyroid subjects and subjects with subclinical hypothyroidism [20]. In contrast, Mehran et al. recently demonstrated a positive correlation between TSH and LDL-cholesterol and TG levels as well as a negative correlation between free thyroxine (T4) and LDL-cholesterol among subjects with normal thyroid function [21]. Currently, there is a lack of consistent results among population-based studies in terms of a correlation between thyroid dysfunction and serum lipid profiles.

In this study, we aimed to study the association between free $\mathrm{T} 4$ within reference ranges and serum lipid profiles in the Korean population using the most recent nationally representative data.

\section{Materials and Methods}

\subsection{Study Subjects}

This study was based on the survey data from the sixth Korea National Health and Nutrition Examination Survey (KNHANES VI), a cross-sectional survey conducted by the Korean Centers for Disease Control and Prevention (KCDC) between 2013 and 2015. KNHANES performs assessments by trained interviewers, monitors the health and nutritional status of the Korean population, and notes the trends in the prevalence of diseases during the survey year. The survey consists of a health interview, health examination and nutritional status. The survey uses stratified, multistage clustered probability sampling. KNHANES was approved by the Institutional Review Board of the KCDC. Written informed consent was acquired from all participants since 1998 [22]. This study was approved by Eunpyeong St, Mary's Hospital Institutional Review Board at the Catholic Medical Center, the Catholic University of Korea (IRB approval No. PC19ZESI0024). Written informed consent was exempted. A total of 8577 subjects were recruited in KNHANES VI.

For our study, 3952 subjects were selected who were older than 19 years and had undergone thyroid function tests and lipid profile testing. Subjects were excluded based on the following criteria: (1) previous therapy for thyroid disease $(n=19)$, (2) abnormal free T4 levels $(<0.82 \mathrm{ng} / \mathrm{mL}$ or $>1.76 \mathrm{ng} / \mathrm{mL})(n=70)$, (3) abnormal TSH levels $(<0.62 \mathrm{mIU} / \mathrm{L}$ or $>6.68 \mathrm{mIU} / \mathrm{L})(n=284),(4)$ current statin therapy $(n=15)$, and (5) treatment for cardiovascular disease $(n=16)$. A total of 3548 subjects were finally selected. 


\subsection{Laboratory Analyses}

Blood and urine samples were collected from all participants. Serum free T4, TSH, and thyroid peroxidase antibodies (TPOAb) were analyzed with electrochemiluminescence immunoassay. Free T4, TSH, and TPOAb levels were measured using an E- free T4 kit (Cobas e 411, Roche Diagnositics GmbH Mannheim, Germany), E-TSH kit (Cobas e 801, Roche Diagnostics GmbH, Mannheim, Germany), and E-Anti-TPO kit (Cobas e 801, Roche Diagnostics GmbH, Mannheim, Germany). The reference ranges for free T4 and TPOAb were 0.89 to $1.76 \mathrm{ng} / \mathrm{mL}$ and $0-34 \mathrm{IU} / \mathrm{mL}$, respectively. As TSH is affected by iodine intake status, and excess iodine is prevalent in Korea [23], serum TSH levels between 0.62 and $6.68 \mathrm{mIU} / \mathrm{L}$, based on population data [24], were considered as reference ranges. Urine iodine concentration was measured by inductively coupled plasma mass spectroscopy (ICP-MS: PerkinElmer ICP-MS, Waltham, USA) and was adjusted for creatinine concentration.

Serum total cholesterol, TG, and HDL-cholesterol were measured by enzymatic methods using a commercial kit (Sekisui, Osaka, Japan) with a Hitachi Automatic Analyzer 7600 (Hitachi, Tokyo, Japan). LDL-cholesterol was calculated using the Friedewald formula: LDL-cholesterol $=$ total cholesterol HDL-cholesterol - (TG/5) [25]. Non-HDL-cholesterol was calculated by subtracting the quantity of HDL-cholesterol from total cholesterol [26].

\subsection{Definition of Other Variables}

Body mass index (BMI) was calculated as weight in kilograms divided by the square of height in meters $\left(\mathrm{kg} / \mathrm{m}^{2}\right)$. Smoking status was defined as never or current smoker. Heavy alcohol consumption was defined as $\geq 210 \mathrm{~g}$ alcohol/week for males and $\geq 140 \mathrm{~g}$ alcohol/week for females. Physical activity was defined as activity consisting of at least $30 \mathrm{~min}$ of walking for at least 5 days a week.

In this study, dyslipidemia was defined as hypertriglycemia (TG $\geq 150 \mathrm{mg} / \mathrm{dL}$ ), high LDL-cholesterol (LDL-cholesterol $\geq 130 \mathrm{mg} / \mathrm{dL}$ ), and low HDL-cholesterol (HDL-cholesterol $\leq 40 \mathrm{mg} / \mathrm{dL}$ for males, $\leq 50 \mathrm{mg} / \mathrm{dL}$ for females) according to the Adult Treatment Panel III Criteria [27].

\subsection{Statistical Analysis}

All statistical analyses were performed using with SAS survey procedures version 9.3 (SAS Institute, Cary, NC, USA). Continuous variables were presented as mean with standard deviation and categorical variables were described in percentages. Comparisons of basic clinical characteristics according to free T4 quartiles were conducted by analysis of variance (ANOVA) testing for continuous variables and the Chi-square test for categorical variables. Univariate linear regression model was used for the association between free T4 quartiles and lipid profiles and multivariate linear regression was performed to control confounding factors such as age, sex, BMI, smoking status, alcohol consumption, urine iodine, TPOAb, and diabetes mellitus. The association was presented as odds ratios (OR) with $95 \%$ confidence intervals. We calculated $p$ values for the trends for the associations in each group by logistic regression analysis inclusive of a trend test. $p$-value $<0.05$ was considered statistically significant.

\section{Results}

\subsection{Baseline Clinical Characteristics of the Subjects in Different Free T4 Groups by Population-Based Reference Range}

Comparisons of clinical characteristics between subjects within the free T4 quartiles are presented in Table 1. Subjects in the highest free T4 quartile were younger than subjects in the other free T4 quartiles. Significant male predominance was observed in the higher quartiles $(51.2 \%$ in Q3 and $70.9 \%$ in Q4) compared with the lower quartiles (43.9\% in Q1 and $52.4 \%$ in Q2, $p<0.001$ ). Habitual factors including alcohol consumption and physical activity were not significantly different between the four groups. However, smoking prevalence was higher in the upper quartiles than that in the lower quartiles $(p<0.001)$. The highest total cholesterol levels were observed in the lowest free T4 quartile. Free T4 levels were negatively correlated with total serum cholesterol levels. Other lipid 
profiles such as TG, HDL-cholesterol, and LDL-cholesterol were not significantly different between the free T4 quartiles. A significant decrease in serum non-HDL-cholesterol levels was observed in the higher free T4 quartiles $(p=0.001)$.

Table 1. Baseline characteristics of the patients based on free T4 levels.

\begin{tabular}{|c|c|c|c|c|c|}
\hline Clinical Parameters & $\begin{array}{c}\text { Q1 } \\
\text { (free T4 } \\
<1.13 \mathrm{ng} / \mathrm{mL} \text { ) }\end{array}$ & $\begin{array}{c}\mathrm{Q} 2 \\
(1.13-1.24 \\
\mathrm{ng} / \mathrm{mL})\end{array}$ & $\begin{array}{c}\text { Q3 } \\
(1.25-1.34 \\
\mathrm{ng} / \mathrm{mL})\end{array}$ & $\begin{array}{c}\mathrm{Q} 4 \\
\text { (free T4 } \\
>1.35 \mathrm{ng} / \mathrm{mL} \text { ) }\end{array}$ & $p$ Value \\
\hline Patients $(n, \%)$ & $877(24.3)$ & $906(25.1)$ & $834(23.4)$ & $931(27.2)$ & \\
\hline Age (years) & $40.1 \pm 0.5$ & $44.9 \pm 0.5$ & $42.2 \pm 0.6$ & $38.5 \pm 0.5$ & $<0.001$ \\
\hline Sex $($ male $n, \%)$ & $295(36.1)$ & $401(47.6)$ & $405(51.2)$ & $635(70.9)$ & $<0.001$ \\
\hline $\operatorname{BMI}\left(\mathrm{Kg} / \mathrm{m}^{2}\right)$ & $23.9 \pm 0.1$ & $24.0 \pm 0.1$ & $23.61 \pm 0.1$ & $23.6 \pm 0.1$ & 0.047 \\
\hline Smoking $(n, \%)$ & $134(16.1)$ & $186(20.4)$ & $192(24.4)$ & $258(28.1)$ & $<0.001$ \\
\hline Heavy alcohol consumption $(n, \%)$ & $99(11.4)$ & $99(11.5)$ & $108(12.8)$ & $125(14.0)$ & 0.395 \\
\hline Physical activity $(n, \%)$ & $144(16.5)$ & $141(14.8)$ & $145(17.7)$ & $169(17.4)$ & 0.460 \\
\hline Diabetes mellitus $(n, \%)$ & $36(3.6)$ & $31(3.3)$ & $35(4.9)$ & $27(2.9)$ & 0.258 \\
\hline Urine iodine: $(\mathrm{mcg} / \mathrm{g})$ & & & & & $<0.001$ \\
\hline $\mathrm{Q} 1(<86.20)$ & $176(20.0)$ & $201(22.7)$ & $204(23.7)$ & $303(32.7)$ & \\
\hline Q2 (86.2-165.4) & $170(18.5)$ & $223(23.7)$ & $234(28.9)$ & $260(28.4)$ & \\
\hline Q3 (165.5-404.3) & $240(28.5)$ & $228(25.7)$ & $207(26.1)$ & $201(20.4)$ & \\
\hline $\mathrm{Q} 4(>404.3)$ & $291(32.9)$ & $254(27.9)$ & $189(21.4)$ & $167(18.4)$ & \\
\hline Total cholesterol (mg/dL) & $193.9 \pm 1.6$ & $192.4 \pm 1.3$ & $189.2 \pm 1.5$ & $187.2 \pm 1.2$ & 0.001 \\
\hline Triglyceride (mg/dL) & $144.4 \pm 6.0$ & $145.4 \pm 5.0$ & $138.2 \pm 4.9$ & $129.4 \pm 4.1$ & 0.056 \\
\hline HDL-cholesterol (mg/dL) & $51.0 \pm 0.5$ & $50.3 \pm 0.4$ & $51.5 \pm 0.5$ & $51.2 \pm 0.5$ & 0.328 \\
\hline LDL-cholesterol (mg/dL) & $114.0 \pm 1.5$ & $113.0 \pm 1.3$ & $110.1 \pm 1.2$ & $110.1 \pm 1.2$ & 0.074 \\
\hline non- HDL-cholesterol (mg/dL) & $142.9 \pm 1.6$ & $142.1 \pm 1.2$ & $137.8 \pm 1.5$ & $136.0 \pm 1.2$ & $<0.001$ \\
\hline
\end{tabular}

\footnotetext{
Data are expressed as mean \pm standard error or number including percentage; Free T4: free thyroxine; BMI: body
} mass index; HDL: high-density lipoprotein; LDL: low-density lipoprotein.

\subsection{Changes in Lipid Profiles According to Free T4 Quartiles}

Total serum cholesterol, LDL-cholesterol and non-HDL cholesterol decreased significantly with higher free T4 quartiles ( $p$ for trend $<0.001,0.013$, and $<0.001$, respectively). However, after adjusting for age, sex, BMI, behavioral patterns, urine iodine, TPOAb positivity, presence of diabetes mellitus, and TSH, the statistical significance disappeared. In contrast, a significant decrease in TG levels and an increase in HDL-cholesterol levels was observed in higher free T4 quartiles after adjusting for possible confounding factors (Table 2).

Table 2. Changes in lipid profiles according to free T4 quartiles.

\begin{tabular}{cccccc}
\hline Lipid Profiles & $\begin{array}{c}\text { Q1 } \\
\text { (free T4 }<\mathbf{1 . 1 3} \\
\mathbf{n g} / \mathbf{m L})\end{array}$ & $\begin{array}{c}\mathbf{Q 2} \\
\mathbf{( 1 . 1 3 - 1 . 2 4} \\
\mathbf{n g} / \mathbf{m L})\end{array}$ & $\begin{array}{c}\text { Q3 } \\
\mathbf{( 1 . 2 5 - 1 . 3 4} \\
\mathbf{n g} / \mathbf{m L})\end{array}$ & $\begin{array}{c}\text { Q4 } \\
\text { (free T4 } \mathbf{1 . 3 5} \\
\mathbf{n g} / \mathbf{m L})\end{array}$ & $\begin{array}{c}p \text { for } \\
\text { Trend }\end{array}$ \\
\hline Total cholesterol (mg/dL) & & & & & \\
Crude & Reference (1.0) & $-1.6 \pm 2.0$ & $-4.7 \pm 2.1$ & $-6.8 \pm 1.9$ & $<0.001$ \\
Model 1 & Reference (1.0) & $-0.4 \pm 2.0$ & $-2.2 \pm 2.1$ & $-2.3 \pm 1.9$ & 0.143 \\
Model 2 & Reference (1.0) & $-0.4 \pm 2.0$ & $-1.5 \pm 2.0$ & $-1.4 \pm 1.9$ & 0.374 \\
Model 3 & Reference (1.0) & $-0.4 \pm 2.0$ & $-1.6 \pm 2.0$ & $-1.3 \pm 1.8$ & 0.378 \\
Model 4 & Reference (1.0) & $-0.3 \pm 2.0$ & $-1.2 \pm 2.0$ & $-1.1 \pm 1.9$ & 0.488 \\
Model 5 & Reference (1.0) & $0.1 \pm 2.0$ & $-0.7 \pm 2.1$ & $-0.5 \pm 1.9$ & 0.395 \\
\hline Triglyceride (mg/dL) & & & & & \\
Crude & Reference (1.0) & $1.0 \pm 7.5$ & $-6.2 \pm 8.0$ & $-15.1 \pm 1.3$ & 0.056 \\
Model 1 & Reference (1.0) & $-5.1 \pm 7.1$ & $-12.5 \pm 7.8$ & $-32.0 \pm 7.8$ & $<0.001$ \\
Model 2 & Reference (1.0) & $-5.3 \pm 7.0$ & $-9.6 \pm 7.7$ & $-27.51 \pm 7.7$ & 0.001 \\
Model 3 & Reference (1.0) & $-4.7 \pm 6.9$ & $-9.8 \pm 7.6$ & $-26.0 \pm 7.6$ & 0.001 \\
Model 4 & Reference (1.0) & $-4.9 \pm 6.9$ & $-11.3 \pm 7.5$ & $-26.9 \pm 7.7$ & 0.001 \\
Model 5 & Reference (1.0) & $-4.8 \pm 7.1$ & $-11.1 \pm 7.7$ & $-26.8 \pm 8.0$ & 0.001 \\
\hline
\end{tabular}


Table 2. Cont.

\begin{tabular}{cccccc}
\hline Lipid Profiles & $\begin{array}{c}\text { Q1 } \\
\text { (free T4 }<\mathbf{1 . 1 3} \\
\text { ng/mL) }\end{array}$ & $\begin{array}{c}\text { Q2 } \\
\mathbf{( 1 . 1 3 - 1 . 2 4} \\
\mathbf{n g} / \mathbf{m L})\end{array}$ & $\begin{array}{c}\mathbf{Q 3} \\
\mathbf{( 1 . 2 5 - 1 . 3 4} \\
\mathbf{n g} / \mathbf{m L})\end{array}$ & $\begin{array}{c}\mathbf{Q 4} \\
\text { (free T4 }>\mathbf{1 . 3 5} \\
\mathbf{n g} / \mathbf{m L})\end{array}$ & $\begin{array}{c}\boldsymbol{p} \text { for } \\
\text { Trend }\end{array}$ \\
\hline HDL-cholesterol (mg/dL) & & & & & \\
Crude & Reference (1.0) & $-0.7 \pm 0.7$ & $0.44 \pm 0.7$ & $0.2 \pm 0.6$ & 0.412 \\
Model 1 & Reference (1.0) & $-0.1 \pm 0.6$ & $1.0 \pm 0.7$ & $1.74 \pm 0.6$ & 0.002 \\
Model 2 & Reference (1.0) & $-0.2 \pm 0.6$ & $0.6 \pm 0.6$ & $1.2 \pm 0.6$ & 0.036 \\
Model 3 & Reference (1.0) & $-0.1 \pm 0.6$ & $0.6 \pm 0.6$ & $1.2 \pm 0.6$ & 0.026 \\
Model 4 & Reference (1.0) & $-0.1 \pm 0.6$ & $0.7 \pm 0.6$ & $1.3 \pm 0.6$ & 0.014 \\
Model 5 & Reference (1.0) & $0.1 \pm 7.6$ & $0.7 \pm 0.6$ & $1.3 \pm 0.6$ & 0.014 \\
\hline LDL-cholesterol (mg/dL) & & & & & \\
Crude & Reference (1.0) & $-1.0 \pm 1.9$ & $-3.9 \pm 2.0$ & $-3.9 \pm 1.2$ & 0.013 \\
Model 1 & Reference (1.0) & $0.7 \pm 1.9$ & $-0.6 \pm 2.0$ & $2.3 \pm 1.9$ & 0.337 \\
Model 2 & Reference (1.0) & $0.8 \pm 1.9$ & $-0.1 \pm 1.9$ & $3.0 \pm 1.8$ & 0.167 \\
Model 3 & Reference (1.0) & $0.6 \pm 1.8$ & $-0.3 \pm 1.9$ & $2.7 \pm 1.8$ & 0.213 \\
Model 4 & Reference (1.0) & $0.8 \pm 1.8$ & $0.4 \pm 1.9$ & $3.0 \pm 1.8$ & 0.129 \\
Model 5 & Reference (1.0) & $1.2 \pm 1.8$ & $0.8 \pm 1.9$ & $3.5 \pm 1.9$ & 0.080 \\
\hline Non-HDL-cholesterol & & & & & \\
(mg/dL) & & & & & \\
Crude & Reference (1.0) & $-0.8 \pm 1.9$ & $-5.2 \pm 2.1$ & $-6.9 \pm 1.9$ & $<0.001$ \\
Model 1 & Reference (1.0) & $-03 \pm 1.9$ & $-3.1 \pm 2.1$ & $-4.1 \pm 1.9$ & 0.013 \\
Model 2 & Reference (1.0) & $-0.2 \pm 1.9$ & $-2.1 \pm 2.0$ & $-2.5 \pm 1.9$ & 0.105 \\
Model 3 & Reference (1.0) & $-0.3 \pm 1.9$ & $-2.3 \pm 2.0$ & $-2.6 \pm 1.8$ & 0.096 \\
Model 4 & Reference (1.0) & $-0.2 \pm 1.9$ & $-1.9 \pm 2.0$ & $-2.4 \pm 1.9$ & 0.133 \\
Model 5 & Reference (1.0) & $0.2 \pm 1.9$ & $-1.4 \pm 2.0$ & $-1.8 \pm 1.9$ & 0.233 \\
\hline
\end{tabular}

The association between free T4 quartiles and lipid profiles were performed by linear regression. Model 1: adjusted for age and sex; Model 2: Model 1 + body mass index; Model 3: Model $2+$ smoking, alcohol consumption, and physical activity; Model 4: Model 3 + urine iodine, peroxidase antibody, and diabetes mellitus; Model 5: Model $4+$ thyrotropin.

\subsection{Risk of Dyslipidemia According to Free T4 Quartiles}

Although higher free T4 quartiles were associated with a decreased risk of dyslipidemia in a crude model, statistical significance was not maintained after adjustment for confounding factors (Table 3). However, the risk of hypertriglyceridemia decreased significantly with the increase in free T4 quartiles after adjustment for confounders ( $p$ for trend $=0.002,0.026,0.043,0.022$, and 0.035 for models 1-5, respectively). Compared with the lowest free T4 quartile, the highest free T4 quartile showed a reduced risk of hypertriglyceridemia with an OR of 0.72 (95\% confidential interval 0.53-0.98) after adjustment for all confounding factors. A decrease in the risk of high LDL-cholesterol was observed with higher free T4 quartiles $(p$ for trend $=0.04$ ). However, significance disappeared after adjustment for confounders. A significant decrease in non-HDL-cholesterol in higher free T4 quartiles was observed only in model 2 (adjustment for age and sex, $p$ for trend $=0.019$ ). 
Table 3. Risk of dyslipidemia according to free T4 quartiles.

\begin{tabular}{|c|c|c|c|c|c|}
\hline $\begin{array}{c}\text { Presence of } \\
\text { Dyslipidemia or Its } \\
\text { Component }\end{array}$ & $\begin{array}{c}\mathrm{Q} 1 \\
\text { (Free T4 }<1.13 \\
\mathrm{ng} / \mathrm{mL})\end{array}$ & $\begin{array}{c}\mathrm{Q} 2 \\
(1.13-1.24 \\
\mathrm{ng} / \mathrm{mL})\end{array}$ & $\begin{array}{c}\mathrm{Q} 3 \\
(1.25-1.34 \\
\mathrm{ng} / \mathrm{mL})\end{array}$ & $\begin{array}{c}\mathrm{Q} 4 \\
\text { (Free } \mathrm{T} 4>1.35 \\
\text { ng/mL) }\end{array}$ & $\begin{array}{l}p \text { for } \\
\text { Trend }\end{array}$ \\
\hline \multicolumn{6}{|l|}{ Dyslipidemia } \\
\hline Crude & Reference (1.0) & $0.90(0.73-1.10)$ & $0.77(0.61-0.97)$ & $0.65(0.53-0.80)$ & $<0.001$ \\
\hline Model 1 & Reference (1.0) & $0.92(0.75-1.13)$ & $0.83(0.66-1.06)$ & $0.74(0.59-0.92)$ & 0.006 \\
\hline Model 2 & Reference (1.0) & $0.92(0.73-1.15)$ & $0.88(0.68-1.14)$ & $0.80(0.63-1.01)$ & 0.072 \\
\hline Model 3 & Reference (1.0) & $0.92(0.74-1.15)$ & $0.87(0.68-1.13)$ & $0.81(0.64-1.03)$ & 0.084 \\
\hline Model 4 & Reference (1.0) & $0.92(0.74-1.15)$ & $0.86(0.67-1.11)$ & $0.80(0.63-1.01)$ & 0.060 \\
\hline Model 5 & Reference (1.0) & $0.92(0.74-1.15)$ & $0.86(0.67-1.12)$ & $0.81(0.64 .1 .02)$ & 0.069 \\
\hline \multicolumn{6}{|l|}{ Hypertriglyceridemia } \\
\hline Crude & Reference (1.0) & $0.99(0.78-1.26)$ & $0.97(0.75-1.25)$ & $0.83(0.65-1.06)$ & 0.125 \\
\hline Model 1 & Reference (1.0) & $0.90(0.70-1.17)$ & $0.89(0.67-1.17)$ & $0.65(0.50-0.86)$ & 0.002 \\
\hline Model 2 & Reference (1.0) & $0.90(0.68-1.18)$ & $0.95(0.71-1.27)$ & $0.71(0.53-0.95)$ & 0.031 \\
\hline Model 3 & Reference (1.0) & $0.90(0.68-1.19)$ & $0.95(0.71-1.27)$ & $0.73(0.54-0.97)$ & 0.047 \\
\hline Model 4 & Reference (1.0) & $0.89(0.67-1.17)$ & $0.92(0.68-1.23)$ & $0.70(0.52-0.95)$ & 0.027 \\
\hline Model 5 & Reference (1.0) & $0.91(0.68-1.20)$ & $0.94(0.69-1.26)$ & $0.72(0.53-0.98)$ & 0.044 \\
\hline \multicolumn{6}{|l|}{ High LDL-cholesterol } \\
\hline Crude & Reference (1.0) & $0.94(0.75-1.18)$ & $0.74(0.57-0.97)$ & $0.82(0.64-1.04)$ & 0.040 \\
\hline Model 1 & Reference (1.0) & $1.01(0.80-1.29)$ & $0.87(0.66-1.15)$ & $1.12(0.87-1.44)$ & 0.665 \\
\hline Model 2 & Reference (1.0) & $1.02(0.80-1.30)$ & $0.90(0.68-1.18)$ & $1.17(0.90-1.51)$ & 0.427 \\
\hline Model 3 & Reference (1.0) & $1.01(0.79-1.28)$ & $0.88(0.67-1.16)$ & $1.14(0.88-1.48)$ & 0.525 \\
\hline Model 4 & Reference (1.0) & $1.02(0.80-1.30)$ & $0.91(0.69-1.20)$ & $1.17(0.90-1.51)$ & 0.386 \\
\hline Model 5 & Reference (1.0) & $1.05(0.82-1.34)$ & $0.94(0.71-1.23)$ & $1.22(0.93-1.58)$ & 0.255 \\
\hline \multicolumn{6}{|l|}{ Non-HDL-cholesterol } \\
\hline Crude & Reference (1.0) & $0.88(0.70-1.12)$ & $0.76(0.59-0.98)$ & $0.66(0.52-0.85)$ & $<0.001$ \\
\hline Model 1 & Reference (1.0) & $0.90(0.70-1.15)$ & $0.82(0.64-1.06)$ & $0.75(0.58-0.97)$ & 0.019 \\
\hline Model 2 & Reference (1.0) & $0.89(0.69-1.15)$ & $0.86(0.66-1.12)$ & $0.80(0.61-1.04)$ & 0.087 \\
\hline Model 3 & Reference (1.0) & $0.89(0.69-1.15)$ & $0.85(0.66-1.11)$ & $0.80(0.61-1.05)$ & 0.086 \\
\hline Model 4 & Reference (1.0) & $0.90(0.70-1.17)$ & $0.88(0.68-1.15)$ & $0.82(0.63-1.07)$ & 0.135 \\
\hline Model 5 & Reference (1.0) & $0.92(0.70-1.19)$ & $0.89(0.68-1.17)$ & $0.84(0.64-1.10)$ & 0.184 \\
\hline
\end{tabular}

The association between free T4 quartiles and dyslipidemia and component of dyslipidemia were performed by logistic regression analysis considering confounders. Dyslipidemia was defined as hypertriglycemia (TG $\geq 150$ $\mathrm{mg} / \mathrm{dL}$ ), high LDL-cholesterol (LDL-cholesterol $\geq 130 \mathrm{mg} / \mathrm{dL}$ ), and low HDL-cholesterol (HDL-cholesterol $\leq 40$ $\mathrm{mg} / \mathrm{dL}$ for males, $\leq 50 \mathrm{mg} / \mathrm{dL}$ for females). Model 1: adjusted for age and sex; Model 2: Model $1+$ body mass index; Model 3: Model 2 + smoking, alcohol consumption, and physical activity; Model 4: Model 3 + urine iodine, peroxidase antibody, and diabetes mellitus; Model 5: Model $4+$ thyrotropin.

\section{Discussion}

In the present study, differences in lipid profiles were evaluated according to free T4 quartiles between subjects with normal thyroid function. Higher free T4 quartiles were associated with a significant decrease in serum TG levels while it was associated with a significant increase in serum high-density lipoprotein (HDL) cholesterol after adjustment for confounding factors. However, there were no significant changes in other lipid profiles including total cholesterol, LDL-cholesterol, and non-HDL-cholesterol based on free T4 quartiles. Regarding the presence of dyslipidemia, the risk of hypertriglyceridemia ( $\geq 150 \mathrm{mg} / \mathrm{dL}$ ) significantly decreased as free T4 quartiles increased. Although some significant correlations were found, no consistent results were observed in the analysis of free T4 quartiles and other parameters of dyslipidemia.

In lipid metabolism, thyroid hormone has significant effects on both influx and efflux of lipid mainly by its action on hepatic lipid processes [1]. Specifically, it facilitates hepatic free fatty acid uptake by upregulation of fatty acid transporting proteins such as fatty acid transporter protein, liver fatty acid binding protein, and fatty acid translocase [28]. De novo lipogenesis, which converts excessive glucose to fatty acid, is also regulated directly and indirectly by thyroid hormone. As increased hepatic fatty acids are related to subsequent triacylglycerol assembly and VLDL production, actions 
of thyroid hormone are crucial for lipid influx [4]. Conversely, thyroid hormone is involved in the degradation of fatty acids, efflux of lipid, by activation of several lipases, lyphophagy, peroxisomal fat oxidation and mitochondrial oxidation [29]. Also, thyroid hormone induces cholesterol biosynthesis by activating hydroxymethylglutaryl coenzyme A reductase, a rate-limiting enzyme, and increases the expression of LDL-cholesterol receptors on the cell surface [10]. Additionally, CETP, which transports cholesteryl esters from HDL-cholesterol to LDL-cholesterol and VLDL, is regulated by thyroid hormone [30]. Thyroid hormone enhances the activity of lipoprotein lipase, which facilitates the hydrolysis of TG containing proteins and the transfer of cholesterol from lipoprotein to HDL-cholesterol [12]. As it controls cholesterol excretion by upregulation of bile acid synthesis and excretion [31], thyroid hormone plays a vital role in cholesterol metabolism in general (from synthesis to clearance). Furthermore, thyroid hormone regulates lipid metabolism of extrahepatic organs such as adipose tissue, intestines and muscle [4]. Thyroid hormone induces lipolysis in adipose tissue by an enhanced catecholamine-mediated mechanism [32]. Excretion of bile acids in intestines, a process related to cholesterol clearance, is promoted by thyroid hormone. Thyroid hormone activates free fatty acid uptake in muscle by increased local lipoprotein lipase activity $[1,33]$. As thyroid hormone is involved in important processes of lipid influx and efflux, its net effects on lipid profiles are difficult to be estimated especially in cases of normal thyroid function. Based on our results, it could be assumed that free $\mathrm{T} 4$ within normal range mainly exerts a positive influence on cholesterol metabolism in terms of TG and HDL cholesterol.

A substantial number of studies demonstrated hypertriglyceridemia and higher levels of LDL-cholesterol in overt hypothyroidism compared with euthyroid subjects [3,12,34]. The effect of overt hypothyroidism on HDL-cholesterol has been controversial [12,14]. In contrast to overt hypothyroidism, there have been conflicting data regarding the relationship between subclinical hypothyroidism and lipid profile alterations. In a small-scale study, significant alternations were not observed in lipid profiles of subjects with subclinical hypothyroidism when compared to euthyroid subjects [34]. By contrast, the Colorado study of 25862 subjects with TSH levels in the reference range suggested that a significant positive correlation exists between total cholesterol, TG, and LDL-cholesterol and increasing TSH [18]. However, these studies did not adjust for age, sex, and BMI, which could affect lipid profiles. A study from the National Health and Nutrition Examination Survey III showed no significant alterations in lipid profiles after adjustment for age, race, sex, and statin use in a subclinical hypothyroid group [15]. In a community-based study involving 2108 participants in Australia, although total cholesterol, TG, and LDL-cholesterol increased with TSH levels, no significant differences were seen in these lipid profiles according to TSH levels after adjustment for age and sex [19]. In contrast to these two studies, the Tromsø study demonstrated a positive correlation between total cholesterol and LDL-cholesterol with TSH levels after adjustment for age, BMI, and smoking status [35]. Various sample size and varying methods for adjustment of confounding factors such as age and other metabolic components could explain the conflicting results from previous studies.

There have been several research projects about an association between TSH and lipid profiles in euthyroidism [19-21,35-40]. Although there have been several studies in euthyroid subjects as mentioned, there have only been a few studies evaluating the association between thyroid hormone (free T4) and lipid profiles. One cross-sectional study in the Netherlands suggested that normal range free T4 showed a negative correlation with total cholesterol, TG, and LDL-cholesterol after adjustment for age and sex, but a positive correlation with HDL-cholesterol in euthyroid subjects (defined as $0.35 \leq \mathrm{TSH} \leq 4.94 \mathrm{mIU} / \mathrm{L}$ ) [18]. However, TSH showed a significant positive correlation with TG only. Another multi-center study evaluated the correlation of lipid profiles with both TSH and free T4 levels in subclinical thyroidisim (defined as $4.5 \leq \mathrm{TSH} \leq 10.0 \mathrm{mIU} / \mathrm{L}$ ) and euthyroid subjects $(0.25 \leq \mathrm{TSH} \leq 4.5 \mathrm{mIU} / \mathrm{L})$ [20]. While serum TSH level showed a positive correlation with total cholesterol and TG, free T4 showed a positive correlation with HDL-cholesterol and a negative correlation with TG in the study. The significant correlation between free T4 and LDL-cholesterol disappeared after adjustment for possible confounding factors such as age and sex. In contrast to a 
previous study [19], de Jesus Garduno-Garci et al [20] suggested that TSH is a more suitable indicator of LDL-cholesterol and TG than free T4. Another study based on data from a prospective and large sample size population reported a correlation between thyroid dysfunction and metabolic marker in subclinical hypothyroidism (TSH $<10 \mathrm{mIU} / \mathrm{L}$ ) and euthyroid $(0.3 \leq \mathrm{TSH} \leq 5.06 \mathrm{mIU} / \mathrm{L}$ ) non-obesity subjects [21]. TSH was positively correlated with total cholesterol, LDL-cholesterol, and TG, while no significant association between TSH and HDL-cholesterol was found. In contrast to the study by de Jesus Garduno-Garci et al. [20], free T4 showed a negative correlation with total cholesterol and LDL-cholesterol and there was no significant difference in TG after adjustment for confounders such age, sex, BMI, and the homeostasis model assessment index for insulin resistance. However, populations used in those studies would not be considered as national representative data. Our study, utilized national representative subjects with normal thyroid function, suggested the association of free T4 with serum triglyceride and HDL-cholesterol levels. In fact, an association of TSH and lipid profiles was also evaluated in our data (Supplementary Table S1 and Table S2) as several previous studies had analyzed. However, compared to analysis of free T4 and lipid profiles, a statistical significance in relationship between TSH and lipid profiles was not definite according to confounding factors.

Recently, a study using KNHANES IV data investigated the association between thyroid dysfunction and lipid profiles according to age and sex [40]. Although the study reported free $\mathrm{T} 4$ as an independent variable for reducing the risk of hypertriglyceridemia, it was analyzed in all subjects, including dose with overt hyperthyroidism and hypothyroidism, who had undergone the thyroid function test. Additionally, in contrast to our study, Oh et. al. [40] did not exclude subjects with taking lipid-lowering agents.

There are some limitations to this study. First, as this study was based on a cross-sectional survey, a causal relationship could be not determined. Second, because laboratory tests were performed only once, inter-individual variations could not be considered. Another limitation is that we could not estimate lipid profiles according to thyronine $\mathrm{T} 3$, which is a biologically active form of thyroid hormone. Data on T3 was not acquired in KNHANES VI.

This study has several strengths. First, although there were several studies elucidating the association between thyroid function and lipid profiles $[3,12,19,20,35-40]$, evaluations of the associations of thyroid hormone (free T4) in euthyroid populations were sparse $[19,20,39,40]$, and our study utilized nationwide representative data. In addition, in contrast to several previous studies [36-38] which reported significant alterations according to TSH without analyzing free T4, our study evaluated associations between free T4 and lipid profiles, and significant relationships were observed. Second, population-based TSH reference ranges were used for defining normal thyroid function as ethnicity and iodine intake could have influenced TSH levels [41]. Third, subjects with a history of cardiovascular disease who would be expected to be taking lipid lowering agents as well as subjects on medication for dyslipidemia were excluded. Additionally, TPOAb, which is related to higher TSH, was considered as a confounding factor [42].

\section{Conclusions}

Thyroid hormones have multiple effects on lipid metabolism. We demonstrated an association between free T4 levels within normal range and dyslipidemia in a nation-wide data. The results of our study suggest that subtle changes in serum free T4 levels, even in the reference ranges, could be related to alterations in lipid profiles, specifically in triglycerides and HDL-cholesterol. In particular, the lowest free T4 quartiles were related to increased risk of hypertriglycemia which is a dyslipidemia component. Further studies are needed to confirm the relationship between thyroid hormones including T3, a biologically active form of thyroid hormone, and lipid profiles. Given our results, cautious monitoring of subjects with normal but relatively low free T4 levels would be required for management of dyslipidemia.

Supplementary Materials: The following are available online at http://www.mdpi.com/2077-0383/8/6/758/s1. 
Author Contributions: Conceptualization, J.L. and M.H.K.; methodology, J.H. and K.J.; software, J.L and M.H.K.; validation, J.L., D.J.L., and M.I.K.; formal analysis, J.L and M.H.K..; data curation, M.H.K..; writing-original draft preparation, J.L.; writing—review and editing, M.H.K.; visualization, J.M.L. and S.A.C.; supervision, M.H.K.

Acknowledgments: This study was partly supported by Clinical Trials Center of St. Paul's Hospital, The Catholic University of Korea. The statistical analysis was conducted by a grant of the Korea Health Technology R\&D Project through the Korea Health Industry Development Institute (KHIDI), supported by Ministry of Health \& Welfare, Republic of Korea (HI14C1062).

Conflicts of Interest: The authors declare no conflict of interest.

\section{References}

1. Sinha, R.A.; Singh, B.K.; Yen, P.M. Direct effects of thyroid hormones on hepatic lipid metabolism. Nat. Rev. Endocrinol. 2018, 14, 259-269. [CrossRef]

2. Hollenberg, A.N. The Role of the Thyrotropin-Releasing Hormone (TRH) Neuron as a Metabolic Sensor. Thyroid 2008, 18, 131-139. [CrossRef] [PubMed]

3. Liberopoulos, E.N.; Elisaf, M.S. Dyslipidemia in patients with thyroid disorders. Hormones (Athens) 2002, 1, 218-223. [CrossRef] [PubMed]

4. Mullur, R.; Liu, Y.-Y.; Brent, G.A. Thyroid Hormone Regulation of Metabolism. Physiol. Rev. 2014, 94, 355-382. [CrossRef] [PubMed]

5. O'Brien, T.; Dinneen, S.F.; O'Brien, P.C.; Palumbo, P.J. Hyperlipidemia in Patients With Primary and Secondary Hypothyroidism. Mayo Proc. 1993, 68, 860-866. [CrossRef]

6. Staub, J.-J.; Althaus, B.U.; Engler, H.; Ryff, A.S.; Trabucco, P.; Marquardt, K.; Burckhardt, D.; Girard, J.; Weintraub, B.D. Spectrum of subclinical and overt hypothyroidism: Effect on thyrotropin, prolactin, and thyroid reserve, and metabolic impact on peripheral target tissues. Am. J. Med. 1992, 92, 631-642. [PubMed]

7. Abrams, J.J.; Grundy, S.M.; Ginsberg, H. Metabolism of plasma triglycerides in hypothyroidism and hyperthyroidism in man. J. Lipid Res. 1981, 22, 307-322.

8. Raziel, A.; Rosenzweig, B.; Botvinic, V.; Beigel, I.; Landau, B.; Blum, I. The influence of thyroid function on serum lipid profile. Atherosclerosis 1982, 41, 321-326. [CrossRef]

9. Heimberg, M.; Olubadewo, J.O.; Wilcox, H.G. Plasma Lipoproteins and Regulation of Hepatic Metabolism of Fatty Acids in Altered Thyroid States*. Endocr. Rev. 1985, 6, 590-607. [CrossRef] [PubMed]

10. Rizos, C.; Elisaf, M.; Liberopoulos, E. Effects of Thyroid Dysfunction on Lipid Profile. Open Cardiovasc. Med. J. 2011, 5, 76-84. [CrossRef]

11. Duntas, L.H. Thyroid Disease and Lipids. Thyroid 2002, 12, 287-293. [CrossRef]

12. Duntas, L.H.; Brenta, G. The Effect of Thyroid Disorders on Lipid Levels and Metabolism. Med Clin. North Am. 2012, 96, 269-281. [CrossRef] [PubMed]

13. Surks, M.I.; Ortiz, E.; Daniels, G.H.; Sawin, C.T.; Col, N.F.; Cobin, R.H.; Franklyn, J.A.; Hershman, J.M.; Burman, K.D.; Denke, M.A. Subclinical thyroid disease: Scientific review and guidelines for diagnosis and management. Jama 2004, 291, 228-238. [CrossRef]

14. Pearce, E.N. Update in Lipid Alterations in Subclinical Hypothyroidism. J. Clin. Endocrinol. Metab. 2012, 97, 326-333. [CrossRef]

15. Vierhapper, H.; Nardi, A.; Grosser, P.; Raber, W.; Gessl, A. Low-Density Lipoprotein Cholesterol in Subclinical Hypothyroidism. Thyroid 2000, 10, 981-984. [CrossRef] [PubMed]

16. Walsh, J.P.; Bremner, A.P.; Bulsara, M.K.; O’Leary, P.; Leedman, P.J.; Feddema, P.; Michelangeli, V. Thyroid dysfunction and serum lipids: a community-based study. Clin. Endocrinol. 2005, 63, 670-675. [CrossRef] [PubMed]

17. Hueston, W.J.; Pearson, W.S. Subclinical Hypothyroidism and the Risk of Hypercholesterolemia. Ann. Fam. Med. 2004, 2, 351-355. [CrossRef]

18. Canaris, G.J.; Manowitz, N.R.; Mayor, G.; Ridgway, E.C. The Colorado Thyroid Disease Prevalence Study. Arch. Intern. Med. 2000, 160, 526. [CrossRef]

19. Roos, A.; Links, T.P.; Wolffenbuttel, B.H.R.; Gans, R.O.B.; Bakker, S.J.L. Thyroid function is associated with components of the metabolic syndrome in Euthyroid Subjects. J. Clin. Endocrinol. Metab. 2007, 92, 491-496. [CrossRef]

20. Garduño-Garcia, J.D.J.; Alvirde-Garcia, U.; López-Carrasco, G.; Mendoza, M.E.P.; Mehta, R.; Arellano-Campos, O.; Choza, R.; Sauque, L.; Garay-Sevilla, M.E.; Malacara, J.M.; et al. TSH and free thyroxine 
concentrations are associated with differing metabolic markers in euthyroid subjects. Eur. J. Endocrinol. 2010, 163, 273-278. [CrossRef]

21. Mehran, L.; Amouzegar, A.; Bakhtiyari, M.; Mansournia, M.A.; Rahimabad, P.K.; Tohidi, M.; Azizi, F.; Mehran, D.L.; Amouzegar, D.A.; Bakhtiyari, D.M.; et al. Variations in Serum Free Thyroxine Concentration Within the Reference Range Predicts the Incidence of Metabolic Syndrome in Non-Obese Adults: A Cohort Study. Thyroid 2017, 27, 886-893. [CrossRef]

22. Kweon, S.; Jang, M.-J.; Kim, Y.; Kim, K.; Choi, S.; Chun, C.; Khang, Y.-H.; Oh, K.; Kim, Y.; Kim, Y. Data Resource Profile: The Korea National Health and Nutrition Examination Survey (KNHANES). Int. J. Epidemiol. 2014, 43, 69-77. [CrossRef]

23. Kim, H.I.; Oh, H.K.; Park, S.Y.; Jang, H.W.; Shin, M.-H.; Kim, S.W.; Kim, T.H.; Chung, J.H. Urinary iodine concentration and thyroid hormones: Korea National Health and Nutrition Examination Survey 2013-2015. Eur. J. Nutr. 2019, 58, 223-240. [CrossRef] [PubMed]

24. Kim, W.G.; Kim, W.B.; Woo, G.; Kim, H.; Cho, Y.; Kim, T.Y.; Kim, S.W.; Shin, M.H.; Park, J.W.; Park, H.L.; et al. Thyroid stimulating hormone reference range and prevalence of thyroid dysfunction in the Korean population: Korea National Health and Nutrition Examination Survey 2013 to 2015. Endocrinol. Metab. (Seoul) 2017, 32, 106-114. [CrossRef]

25. Friedewald, W.T.; I Levy, R.; Fredrickson, D.S. Estimation of the concentration of low-density lipoprotein cholesterol in plasma, without use of the preparative ultracentrifuge. Clin. Chem. 1972, 18, 499-502.

26. Frost, P.H.; Havel, R.J. Rationale for Use of Non-High-Density Lipoprotein Cholesterol Rather Than Low-Density Lipoprotein Cholesterol as a Tool for Lipoprotein Cholesterol Screening and Assessment of Risk and Therapy. Am. J. Cardiol. 1998, 81, 26B-31B. [CrossRef]

27. Grundy, S.; Becker, D.; Clark, L.; Cooper, R.; Denke, M.; Howard, J.; Hunninghake, D.; Illingworth, D.; Luepker, R.; McBride, P. Detection, evaluation, and treatment of high blood cholesterol in adults (Adult Treatment Panel III). Circulation 2002, 106, 3143-3421.

28. Quiroga, A.D.; Lehner, R. Liver triacylglycerol lipases. Biochim. Biophys. Acta 2012, 1821, 762-769. [CrossRef]

29. Berg, E.H.V.D.; Van Tienhoven-Wind, L.J.; Amini, M.; Schreuder, T.C.; Faber, K.N.; Blokzijl, H.; Dullaart, R.P. Higher free triiodothyronine is associated with non-alcoholic fatty liver disease in euthyroid subjects: The Lifelines Cohort Study. Metab. Clin. Exp. 2017, 67, 62-71. [CrossRef]

30. Vaitkus, J.A.; Farrar, J.S.; Celi, F.S.; Ross, J.M.; Coppotelli, G. Thyroid Hormone Mediated Modulation of Energy Expenditure. Int. J. Mol. Sci. 2015, 16, 16158-16175. [CrossRef]

31. Li, T.; Francl, J.M.; Boehme, S.; Chiang, J.Y. Regulation of cholesterol and bile acid homeostasis by the cholesterol $7 \alpha$-hydroxylase/steroid response element-binding protein 2/microRNA-33a axis in mice. Hepatology 2013, 58, 1111-1121. [CrossRef]

32. Sinha, R.A.; Singh, B.K.; Yen, P.M. Thyroid hormone regulation of hepatic lipid and carbohydrate metabolism. Trends Endocrinol. Metab. 2014, 25, 538-545. [CrossRef] [PubMed]

33. Biondi, B.; Wartofsky, L. Treatment with thyroid hormone. Endocr. Rev. 2014, 35, 433-512. [CrossRef]

34. Bell, R.J.; Davison, S.L.; Topliss, D.J.; Donath, S.; Davis, S.R.; Rivera-Woll, L.; Rivera-Woll, L. Well-being, health-related quality of life and cardiovascular disease risk profile in women with subclinical thyroid disease ? A community-based study. Clin. Endocrinol. 2007, 66, 548-556. [CrossRef]

35. Iqbal, A.; Jorde, R.; Figenschau, Y. Serum lipid levels in relation to serum thyroid-stimulating hormone and the effect of thyroxine treatment on serum lipid levels in subjects with subclinical hypothyroidism: The Tromso Study. J. Intern. Med. 2006, 260, 53-61. [CrossRef] [PubMed]

36. Park, S.B.; Choi, H.C.; Nam, S.-J. The relation of thyroid function to components of the metabolic syndrome in Korean men and women. J. Korean Med. Sci. 2011, 26, 540-545. [CrossRef]

37. Asvold, B.O.; Vatten, L.J.; Nilsen, T.I.; Bjøro, T. The association between TSH within the reference range and serum lipid concentrations in a population-based study. The HUNT Study. Eur. J. Endocrinol. 2007, 156, 181-186. [CrossRef] [PubMed]

38. Oh, J.-Y.; Sung, Y.-A.; Lee, H.J. Elevated thyroid stimulating hormone levels are associated with metabolic syndrome in euthyroid young women. Korean J. Intern. Med. 2013, 28, 180-186. [CrossRef]

39. Wanjia, X.; Chenggang, W.; Aihong, W.; Xiaomei, Y.; Jiajun, Z.; Chunxiao, Y.; Jin, X.; Yinglong, H.; Ling, G. A high normal TSH level is associated with an atherogenic lipid profile in euthyroid non-smokers with newly diagnosed asymptomatic coronary heart disease. Lipids Heal. 2012, 11, 44. [CrossRef] 
40. Oh, H.S.; Kwon, H.; Ahn, J.; Song, E.; Park, S.; Kim, M.; Han, M.; Jeon, M.J.; Kim, W.G.; Kim, W.B.; et al. Association between thyroid dysfunction and lipid profiles differs according to age and sex: Results from the Korean National Health and Nutrition Examination Survey. Thyroid 2018, 28, 849-856. [CrossRef]

41. Biondi, B. The normal TSH reference range: What has changed in the last decade? J. Clin. Endocrinol. Metab. 2013, 98, 3584-3587. [CrossRef] [PubMed]

42. Spencer, C.A.; Hollowell, J.G.; Kazarosyan, M.; Braverman, L.E. National Health and Nutrition Examination Survey III thyroid-stimulating hormone (TSH)-thyroperoxidase antibody relationships demonstrate that TSH upper reference limits may be skewed by occult thyroid dysfunction. J. Clin. Endocrinol. Metab. 2007, 92, 4236-4240. [CrossRef] [PubMed]

(C) 2019 by the authors. Licensee MDPI, Basel, Switzerland. This article is an open access article distributed under the terms and conditions of the Creative Commons Attribution (CC BY) license (http://creativecommons.org/licenses/by/4.0/). 